\title{
Facilitating student compliance into professional concordance
}

\section{Introduction}

Patient compliance has been a major consideration within the nursing field with regards to intended outcomes and patient satisfaction in care rendered. Becker \& Maiman ${ }^{1}$ noted that non-compliance is a major barrier between patients achieving therapeutic outcomes. Compliance is conceptualized as the adherence to the specifications dictated by a medical professional. Often these interventions are in direct conflict with significant patient considerations that result in noncompliance. Alikari \& $\mathrm{Zyga}^{2}$ suggest that compliance has undergone a connotative evolution from adherence to medical treatment to a focus on the patient's autonomy and participation in their own care. It is important to note that compliance has a universal connotation related to an adhering to a standard. Instead of care being rendered in terms of dictated interventions, a dialogue should be initiated to assess the patient's priorities with regards to their healthcare and overall wellbeing. Concordance is a synergistic collaboration between the provider and patient in which the patient's wishes and intentions are held paramount.

\section{Relevance to the nursing field}

Currently, patient compliance to prescribed plans of care is a subject of great interest to the field. ${ }^{3}$ Consequentially, many articles have been written in the pursuit of improving patient compliance as their main objective. ${ }^{4-6}$ Lack of compliance to plans of care is noted as being a major factor in rising healthcare costs. ${ }^{7}$ When healthcare interventions are not implemented, often medical conditions worsen or result in acute exacerbations. As a medical issue progresses, costs typically become more substantial. The prevailing method of intervention to achieve positive patient outcomes has been focused on improving compliance to evidence-based best care practices.

\section{Student compliance to professional concordance}

The concept of compliance is a fundamental tenet in the development of nursing students. Much of what a nursing student is taught centers on the identification of parameters and staying within the accepted scope of practice. The nursing profession is a unique blend of science and art. Where a nursing student identifies the objective facts related to a subject, the professional nurse advancing his or her education while engaging in complementary work experience may be able to focus efforts on improving care and thinking critically to master higher level operations within the nursing field. A nurse will grow out of the compliance phase of his or her professional career and will be able to integrate his or her practice with the same positive characteristics that are beneficial in everyday life. Such characteristics include integrity, compassion, critical thinking, and altruism. This progression of professional growth is consistent with Benner's Novice to Expert theory. ${ }^{8}$ Nurses should not make a direct correlation between the need for compliance during their own education and a necessity for compliance from patients related to their own care. Successful nursing professionals' practice will become concordant with patientcentered outcomes and evidence-based best interventions.
Volume 3 Issue 2 - 2019

\author{
Douglas Kemerer \\ Lecturer of Nursing, York College of Pennsylvania, USA
}

Correspondence: Douglas Kemerer, Lecturer of Nursing, York College of Pennsylvania, USA, Email Dkemerer@gmail.com

Received: August 04, 2018 | Published: March 13, 2019

\section{Conceptual limitations of compliance}

Barofsky ${ }^{9}$ proposes that there are three stages along the social interactive continuum. These three stages are coercion, conformity, and negotiation. Coercion is a tactic that should never be implemented by the professional nurse due to the patient's unalienable right for autonomy and integrity. Conformity is an outcome that lacks modern conceptual nursing theories rooted in holism and individualized needs. Negotiation is a proper tactic for the professional nurse to implement, yet even this social interaction is often rendered with the presumption of medical/empirical data at the foundation. Dracup \& Melens ${ }^{10}$ note that the most substantive nursing interventions will not be effective if the patient chooses not to participate with the plan of care. Nursing professionals must advocate for a patient's personal considerations by rooting all care modules on patient preference and individualized needs.

Unlike nursing professionals whom have an obligation to comply with standards of care, there is no objective standard by which patients must act according to a nursing professional's opinion. This is because the optimal outcome is based solely on the subjective preference of the patient. Often, nursing professionals presume that cure or an alleviation of symptoms is objectively the optimal outcome. The concept of compliance implicitly suggests that the prescribed medical intervention is indefinitely the best based on empirical data and peer-reviewed sources. This leads to a break in the therapeutic rapport between the professional nurse and patient due to paternalism. There are many other considerations that must be taken into account. A nursing professional may cause mental, spiritual, or emotional harm by insisting that a patient comply with a prescribed treatment regimen. For example, a Jehovah's Witness whom sustains a massive hemorrhage secondary to a motor vehicle accident must be treated in a holistic manner. While the treatment of choice is a blood transfusion which is empirically the best intervention for this situation, spiritual harm would be implemented if the patient identifies that he or she refuses the intervention based on spiritual beliefs. ${ }^{11}$

\section{Interventions that promote concordance}

Simons ${ }^{12}$ developed a system to promote patient concordance which centers on five intervention modules: behavior modification, coping enhancement, mutual goal setting, patient contracting, and self-modification. Self-modification is completely subjective and up to the individual to find value in this intervention. Patient contracting is an intervention that is implicitly paternalistic due to the default of 
placing moral superiority on the professional expertise of the nurse. Behavior modification, coping enhancement, and mutual goal setting are effective modalities for nurses to facilitate patient autonomy and engagement with achieving optimal levels of wellness.

A major consideration for improving patient concordance with a treatment plan is to implement interventions that are in agreement with the patient's current lifestyle. For example, by decreasing the frequency of a medication it may minimize the risk for the patient to miss medication administrations. ${ }^{13}$ Another intervention that may increase the chance of patient concordance is to follow-up with a communication media that is congruent with the patient's preference such as telephone or email to remind patients of salient instructions after a procedure. ${ }^{14}$

Therapeutic communication is another major factor that promotes concordance. The manner in which education and medical information is presented has a large effect on how a patient will respond. Therapeutic communication is rooted in the tenets of rendering focused attention with a pleasant yet neutral affect while attempting to facilitate the patient towards their highest level of wellness.

Lack of concordance often occurs due to socioeconomic deficiencies such as cost of medications or lack of social support. Nurses should advocate for their patients in regards to the use of generic medications where possible or the discontinuation of supplementary or non-essential medications. Porter ${ }^{15}$ observed that social isolation had a significant negative correlation related to adherence to chronic medication administration. There can be greater effort taken by case managers and visiting nurses to provide meaningful and substantive social interactions to those patients whom live alone.

\section{Attaining patient centered and evidence based best outcomes}

The goal of any healthcare entity's mission should not be centred on patient compliance to the plan of care. Compliance is an inherently paternalistic concept that often belittles an individual's autonomy and may serve as a major barrier to patient-provider rapport. Concordance is a process in which the patient's individualized needs are held in highest esteem and the whole conceptualization of wellness is based on the patient's wishes. Where compliance demands adherence to a mandate, concordance is an ultimate understanding reached through thoughtful compromise. Patients have been found to feel more optimistic and have greater satisfaction in the care rendered when the provider and patient's goals are aligned. ${ }^{16} \mathrm{~A}$ focus on optimizing the methods by which information is disseminated from provider to patient should be a major goal. Lawn ${ }^{17}$ argues that the bottom line in healthcare is not 'the patient taking the correct medication at the correct time and at the correct dose' as Fraser ${ }^{18}$ suggests but rather is that whatever treatment is implemented "should suit the patient's needs and actually ameliorate or cure the health condition for which the patient has come to seek help, while minimizing other unwanted effects, as experienced and tolerated by the patient". This serves as an appropriate clinical definition for how nursing professional-patient concordance should occur.

\section{Acknowledgments}

None.

\section{Conflicts of interest}

The authors declare there is no conflicts of interest.

\section{References}

1. Becker M, Maiman L. Strategies for enhancing patient compliance. $J$ Community Health. 1980;6(2):113-135.

2. Alikari V, Zyga S. Conceptual analysis of patient compliance in treatment. Health Science Journal. 2014;8(2):179.

3. Kim K, Chin G, Moore T, et al. Does a preoperative educational class increase patient compliance. Geriatr Orthop Surg Rehabil. 2015;6(3):153156.

4. Hahn MB. Patient compliance; wherefore art thou? Am $J$ Bioeth. 2010;10(11):13-14.

5. Sethi W. Improving patient compliance: C-19374 O/D/CL. Optometry Today. 2012;52(16):51.

6. Lewis K. Improving patient compliance with diabetic retinopathy screening and treatment. Community Eye Health. 2015;28(92):68-69.

7. Cortesi E, Mencacci C, Luigi F, et al. Compliance, persistence, costs and quality of life in young patients treated with antipsychotic drugs: Results from the COMETA study. BMC Psychiatry. 2013;13(1):98.

8. Benner P. From novice to expert: excellence and power in clinical nursing practice. Menlo Park, California: Addison-Wesley; 1984.

9. Barofsky I. Compliance, adherence and the therapeutic alliance steps in the development of care. Soc Sci Med. 1978;12(5A):369-376.

10. Dracup K, Meleis A. Compliance an interactionist approach. Nurs Res. 1982;31(1):31-36.

11. Doyle DJ. Jehovah's witnesses and blood transfusions. CMAJ. 1998;158(6):717-718.

12. Simons M. Interventions related to compliance. Nurs Clin North Am. 1992;27(2):477-494.

13. Paes AH, Bakker A, Soe-Agnie CJ. Impact of dosage frequency on patient compliance. Diabetes Care. 1997;20(10):1512-1517.

14. Chen M, Li P, Lin F. Influence of structured telephone follow-up on patient compliance with rehabilitation after total knee arthroplasty. Patient Prefer Adherence. 2016;10:257-264.

15. Porter A. Drug defaulting in a general practice. $\mathrm{Br}$ Med $\mathrm{J}$. 1969;1(5638):218-222.

16. Street $\mathrm{Jr} \mathrm{R}$. Understanding concordance in patient-physician relationships: Personal and ethnic dimensions of shared identity. Ann Fam Med. 2008;6(3):198-205.

17. Lawn S. Compliance, concordance, and patient-centered care. Patient Prefer Adherence. 2011;5:89-90.

18. Frasier S. Concordance, compliance, preference or adherence. Patient Prefer Adherence. 2010;4:95-96. 